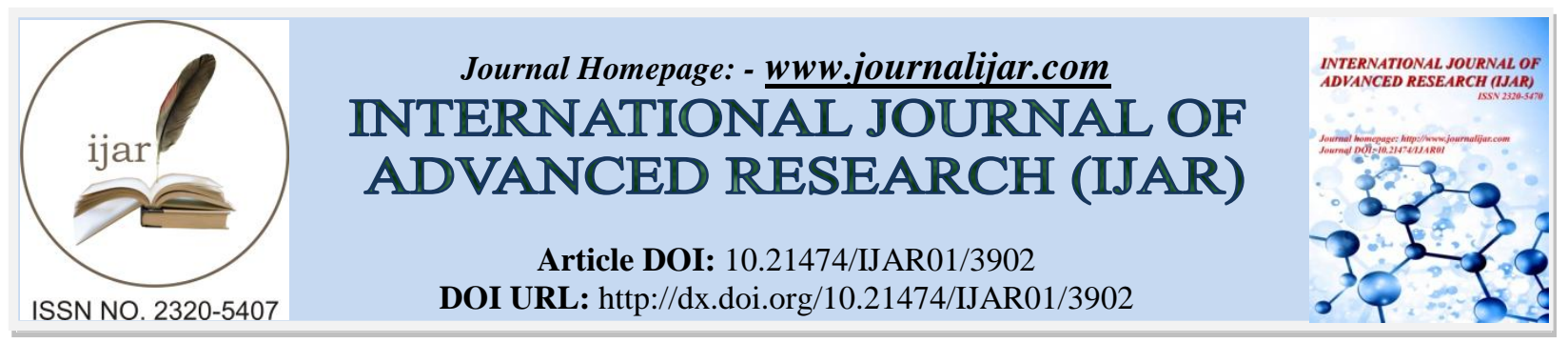

RESEARCH ARTICLE

\title{
STRUCTURAL AND PHOTOLUMINESCENCE PROPERTIES OF Fe-DOPED ZnO THIN FILMS
}

\author{
T. Srinivasulu, K. Saritha and "K.T. Ramakrishna Reddy.
}

Solar Photovoltaic Laboratory, Department of Physics, Sri Venkateswara University, Tirupati - 517 502, India.

\section{Manuscript Info}

Manuscript History

Received: 15 February 2017

Final Accepted: 16 March 2017

Published: April 2017

Key words:-

Spray pyrolysis, ZnO:Fe films, XRD

spectra, SEM micrographs and

Photoluminescence.

\begin{abstract}
In the present study, the chemical spray pyrolysis method has been taken for synthesis of iron doped zinc oxide ( $\mathrm{ZnO}: \mathrm{Fe})$ thin films. All the films have been deposited at a constant substrate temperature of $400^{\circ} \mathrm{C}$ and the dopant (iron) concentration varied in the range, $0-6$ at. $\%$. The X-ray diffraction (XRD) spectra of all as-grown films showed the existence of hexagonal wurtzite crystal structure without any other impurity phases. However, the predominant orientation changed from (002) to (101) plane with the increase of doping concentration. The surface morphology of as-prepared $\mathrm{ZnO}$ :Fe samples were viewed by scanning electron microscopy (SEM), which showed irregular shaped grains distributed over the substrate surface. The photoluminescence spectra exhibited UV-Visible and green emissions with suppressed intensity with the rise of $\mathrm{Fe}$-content in the films.
\end{abstract}

Copy Right, IJAR, 2017. All rights reserved.

\section{Introduction:-}

The application of zinc oxide ( $\mathrm{ZnO}$ ) thin films is not limited to use as (i) an antireflection coating in inorganic photovoltaic cell [1], but also as (ii) an electron transport material in dye sensitized and hybrid solar cells (DSC and HSC) [2], (iii) an optical spacer in polymer solar cell [3] (iv) planar displays because of good transparency, suitable refractive index and have potential to form textured deposition via anisotropic growth [4] and also (v) an interesting material for designing semiconductor devices [5]. Recently, $\mathrm{ZnO}$ is emerged as an alternating material to tin doped indium oxide (ITO) and tin oxide $\left(\mathrm{SnO}_{2}\right)$ thin films, which are used as transparent conducting oxide (TCO) layers in solar cell applications [6,7]. Because of its low cost, non-toxicity, huge availability, direct and wide band gap (3.37 $\mathrm{eV}$ ) at room temperature, high optical transmittance mostly in Vis-NIR region makes it a potential material for optoelectronic device applications like laser diodes, light emitting diodes and photo sensors [8]. However, the investigations on properties of pure and doped $\mathrm{ZnO}$ films still attracts the attention of many researchers. The physical characteristics of $\mathrm{ZnO}$ films can be controlled by either adequate doping or annealing processes. Various dopants like aluminum ( $\mathrm{Al})$, indium $(\mathrm{In})$, boron $(\mathrm{B})$, copper $(\mathrm{Cu})$, gallium $(\mathrm{Ga})$, molybdenum $(\mathrm{Mo})$, iron $(\mathrm{Fe})$, magnesium $(\mathrm{Mg})$, chromium $(\mathrm{Cr})$, cobalt $(\mathrm{Co})$ and nickel $(\mathrm{Ni})$ have been used in the literature in order to deposit high conductivity $\mathrm{ZnO}$ films. Out of these, iron (Fe) (transition metal) doped $\mathrm{ZnO}$ has been recognized as a promising material [9-11]. In general, Fe-doped ZnO (FZO) films exhibit n-type electrical conductivity with hexagonal wurtzite crystal structure along with reduced band gap from $3.3 \mathrm{eV}$ to $2.75 \mathrm{eV}$ [12-14].

Several chemical and physical techniques have been used for the preparation of FZO thin films such as sol-gel [13], chemical synthesis [15], hydrothermal and calcination [16], solution combustion method [17], liquid polyols [18], spray pyrolysis [19], RF - magnetron sputtering [20] and pulsed laser deposition [21]. Compared to other techniques, spray pyrolysis is a simple, vacuum free, cost effective and wet chemical method for easy deposition of 
thin films over large areas. Moreover, incorporation of dopants into the films is easier using this technique. However, very few reports are available on the detailed investigation on structural and optical properties of spray deposited Fe-doped $\mathrm{ZnO}$ thin films. Therefore, in the present work, the structural, morphological and photoluminescence properties of spray deposited iron doped zinc oxide thin films prepared at various doping concentrations were reported and discussed.

\section{Experimental and characterization details:-}

The schematic representation of spray pyrolysis process used to prepare pure and Fe-doped $\mathrm{ZnO}$ thin films is as shown in figure 1. All the precursors used for the preparation of solution were of $99.9 \%$ purity, purchased from Sigma Aldrich Company. Initially, $300 \mathrm{ml}$ aqueous of $0.1 \mathrm{M}$ concentration was prepared by dissolving zinc acetate dihydrate $\left(\mathrm{Zn}\left(\mathrm{CH}_{3} \mathrm{COOH}\right)_{2} \cdot 2 \mathrm{H}_{2} \mathrm{O}\right)$ and ferric chloride $\left(\mathrm{FeCl}_{3}\right)$ in distilled water and then stabilized the solution by adding few drops of acetic acid $\left(\mathrm{CH}_{3} \mathrm{COOH}\right)$ while stirring the solution using magnetic stirrer for 45 minutes at room temperature only. Then the as-prepared solution was sprayed on ultrasonically cleaned and preheated Corning 7059 glass substrates in order to grow Fe-doped $\mathrm{ZnO}$ (FZO) thin films. In the process of preparing FZO films, only Fe-doping concentration was varied in the range, $0-6$ at. \% while the other deposition parameters such as substrate temperature $\left(400^{\circ} \mathrm{C}\right)$, distance between nozzle to substrate $(30 \mathrm{~cm})$, compressed air flow rate $\left(2.5 \mathrm{~kg} / \mathrm{cm}^{2}\right)$ and final solution flow rate $(5 \mathrm{ml} / \mathrm{min}$.) were kept constant throughout the deposition of films. The solution was sprayed for 90 minutes with regular gap intervals of few seconds to overcome the cooling of substrates and to keep the substrate temperature at desired temperature throughout the deposition. The substrate temperature was monitored by using a copper - constantan thermocouple. After completion of spraying process, the grown thin films were collected when the substrate temperature was cooled to room temperature.

Finally, the structural details of FZO films were examined by using Siefert X-ray diffractometer (XRD) with Cu K $\alpha$ radiation (wavelength of $1.540 \AA$ ), while the surface morphological properties were studied using Carl Zeiss scanning electron microscope (SEM) and the photoluminescence properties were analyzed through Renishaw photoluminescence spectrophotometer measurements.

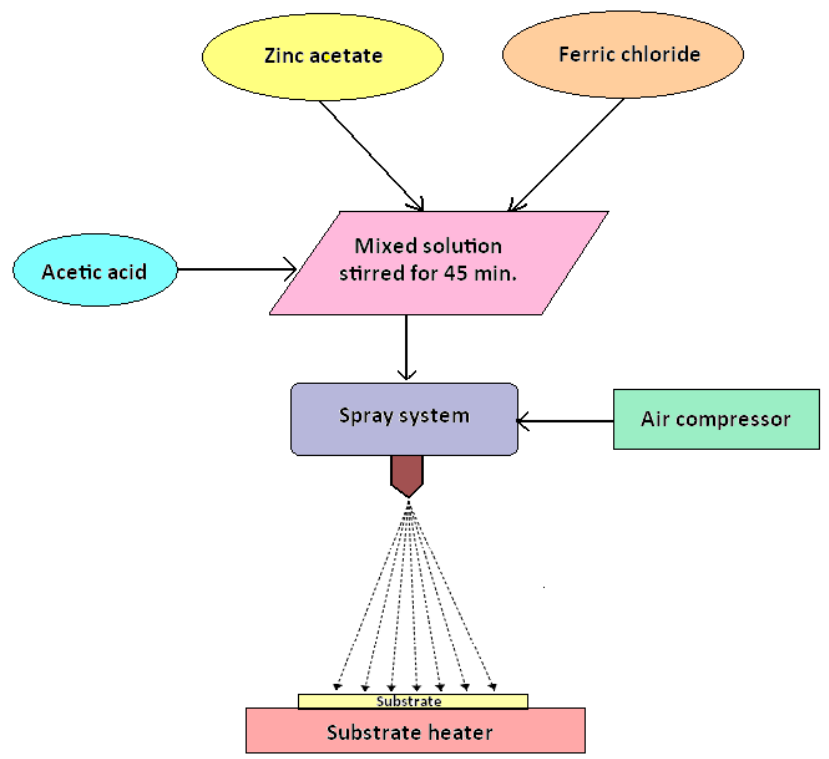

Fig. 1:- Spray pyrolysis deposition of Fe-doped $\mathrm{ZnO}$ thin films.

\section{Results and discussion:-}

All the as-coated films were of nearly $200 \mathrm{~nm}$ thick, uniform, pin-hole free for visual inspection of the films and showed good adhesion over the substrate surface as revealed by scratch tape test. Also the pure ZnO thin films were pale milky white in colour whereas the Fe-doped $\mathrm{ZnO}$ films were in light brown and the colour variation of the films was increased with increase of Fe-content in the films. The effect of Fe-doping concentration on structural and photoluminescence properties of $\mathrm{ZnO}$ films was analyzed and discussed. 


\section{Structural studies:-}

The X-ray diffraction spectra of as-grown pure and Fe-doped $\mathrm{ZnO}$ films were shown in figure 2.The XRD patterns revealed that all the grown films were polycrystalline in nature, showing multiple peaks corresponding to (100), (002), (101), (102), (103), (110) and (112) planes related to the hexagonal wurtzite crystal structure. All these observed peaks are very well matched with the peaks in the JCPDS card no: 89-0510. Irrespective of doping concentration, all the films showed peaks similar to pure $\mathrm{ZnO}$, which indicates that no structural deformation occurred in $\mathrm{ZnO}$ lattice upon Fe-doping. This confirms the successful substitutional replacement of Fe ions in $\mathrm{Zn}$ lattice sites in the $\mathrm{ZnO}$ matrix. However, a change in the preferred orientation from (002) to (101) plane was noticed while increasing the doping concentration $\geq 2$ at. $\%$ that might be due to the presence of high Fe content in the films. Alver et al. [22] also observed a similar shift in preferred orientation, but from (100) to (002) plane for highly Fedoped $\mathrm{ZnO}$ thin films coated by ultrasonic spray pyrolysis method. It is also observed from the XRD patterns that the intensity of peaks was reduced at lower doping concentration upto 2 at. $\%$ and then increased. This variation in peak intensity directly shows the impact of doping concentration on surface texture of the films. Similar increase of peak intensity with Fe-doping was observed by Rambu et al. [13] for Fe-doped ZnO films deposited by spin coating technique, who reported that the deposition method, deposition parameters and the distribution of Fe ions in $\mathrm{ZnO}$ matrix influence the crystalline quality and growth orientation of $\mathrm{ZnO}: \mathrm{Fe}$ films.

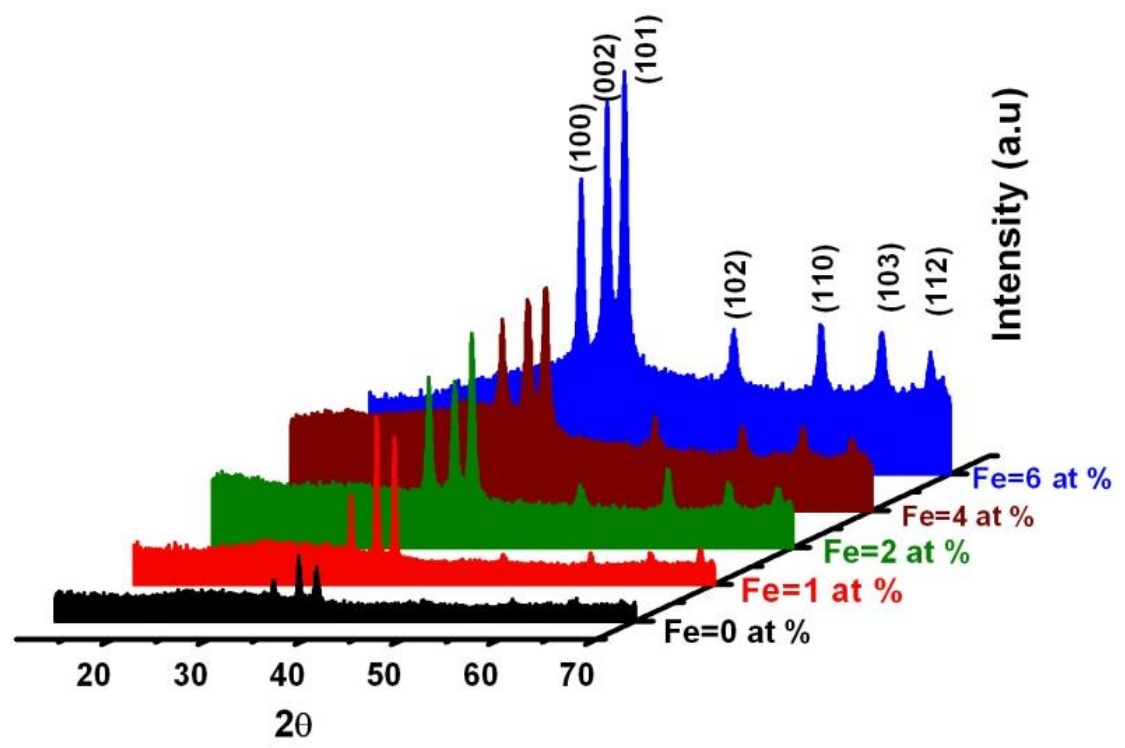

Fig.2:- X-ray diffraction spectra of pure and Fe-doped $\mathrm{ZnO}$ thin films.

The lattice parameters were evaluated by using the appropriate formulae mentioned in relations (1-3) as available in the literature on hexagonal crystal structure [23,24]. It is found that the values of lattice constants (a and c) and inter-planar spacing (d) were decreased with increase of Fe-doping. From the evaluated values, it is clear that $\mathrm{ZnO}$ films doped with 1 at. \% of Fe showed very less variation in the lattice parameters with a=2.946 $\AA$, c= $5.103 \AA$ and $\mathrm{d}=2.551 \AA$ compared to pure $\mathrm{ZnO}$ films that had $\mathrm{a}=2.951 \AA, \mathrm{c}=5.111 \AA$ and $\mathrm{d}=2.555 \AA$. This change in lattice parameters might be due to the substitutional replacement of $\mathrm{Fe}^{3+}$ impurity ions in the place of $\mathrm{Zn}^{2+}$ ionic sites in $\mathrm{ZnO}$ matrix, which causes a small misfit because of different ionic radius of Fe ions compared to $\mathrm{Zn}$ ions. The other structural parameters such as crystallite size (D), dislocation density $(\delta)$, lattice micro strain $(\varepsilon)$ and texture coefficient $\left(\mathrm{T}_{\mathrm{c}}\right)$ were also evaluated using the relations (4-7) [25] where the symbols have their usual meaning. The variation of different structural parameters with respect to Fe-doping concentration was as shown in figure 3 and 4. It can be seen that $\mathrm{ZnO}$ film with $\mathrm{Fe}=1$ at. $\%$ showed large crystallite size, high texture coefficient and less lattice strain than the other Fe-concentrations in the host $\mathrm{ZnO}$ films. Therefore, $\mathrm{Fe}=1$ at. \% is the optimized doping concentration into $\mathrm{ZnO}$ layers for better structural characteristics.

$a=\frac{\lambda}{\sqrt{3} \sin \theta}$ 


$$
\begin{aligned}
& c=\frac{\lambda}{\sin \theta} \\
& \frac{1}{d_{h k l}^{2}}=\left[\frac{4}{3}\left(h^{2}+k^{2}+l^{2}\left(\frac{a}{c}\right)^{2}\right)\right] \frac{1}{a^{2}}
\end{aligned}
$$

where, $\lambda$ is wavelength of $\mathrm{X}$ - rays $(1.540 \AA), \theta$ is diffraction angle and $\mathrm{h}, \mathrm{k}, 1$ are miller indices.

$$
\begin{aligned}
& D=\frac{0.94 \lambda}{\beta \cos \theta} \\
& \delta=\frac{1}{D^{2}} \\
& \varepsilon=\frac{\beta \cos \theta}{4}
\end{aligned}
$$

where, $D$ is crystallite size, $\beta$ is full width at half maxima, $\delta$ is dislocation density, $\varepsilon$ is lattice strain.

Texture coefficient, $T_{C}=\frac{\frac{I(h k l)}{I_{0}(h k l)}}{\sum_{n} \frac{I(h k l)}{I_{0}(h k l)}} \times 100 \%$

where, $I(h k l)$ is the measured relative intensity of preferred orientation plane (hkl), $I_{0}(h k l)$ is the standard intensity of the preferred orientation (hkl) taken from JCPDS data and $n$ is number of diffraction peak considered.

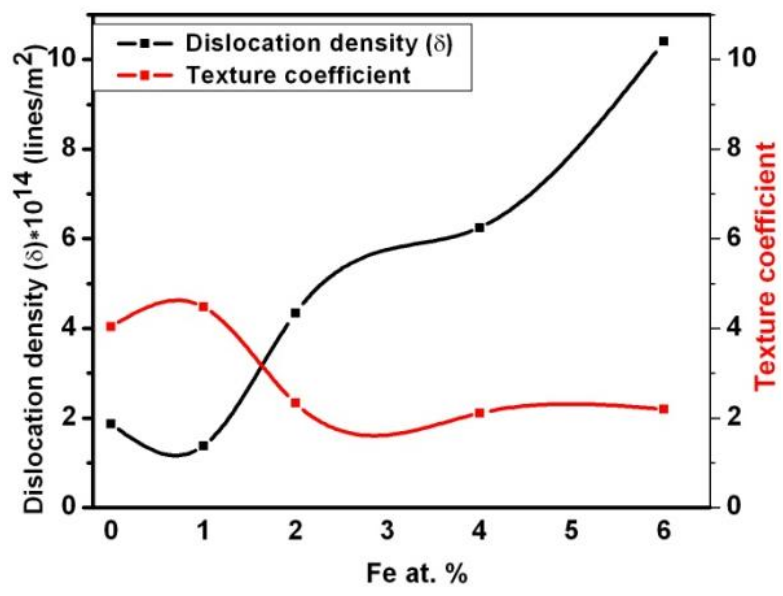

Fig. 3:- Variation of $\delta$ and T.C. of FZO films with Fe-content.

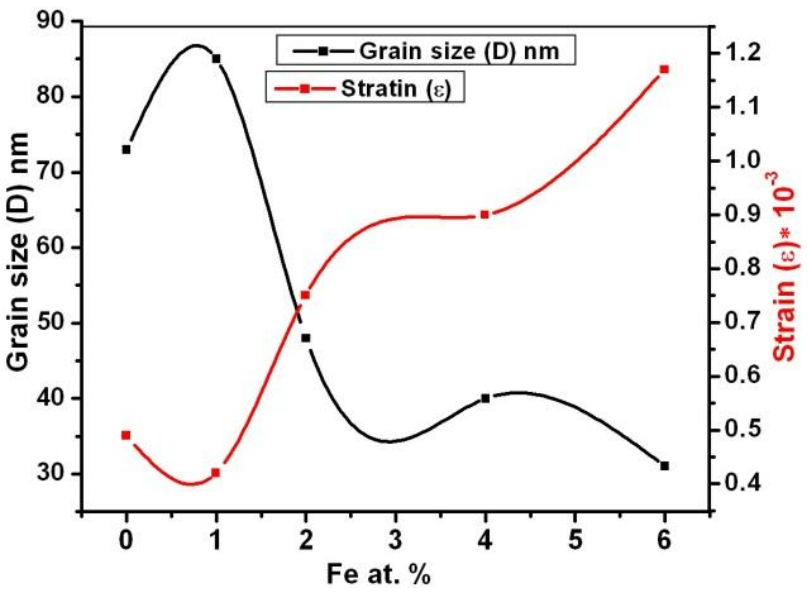

Fig.4: Variation of D and $\varepsilon$ of FZO films with Fe-content.

\section{Morphological studies:-}

The surface morphological properties of as-deposited films were analyzed by using scanning electron microscopy (SEM) at $10 \mathrm{Kx}$ magnification with $1 \mu \mathrm{m}$ resolution and the obtained images of pure and $\mathrm{Fe}=1$ at. \% doped $\mathrm{ZnO}$ films were shown in figure 5. The micrographs clearly depicted the impact of Fe-doping on the surface morphology of the films. The SEM micrographs of lightly doped $(<2$ at. \%) $\mathrm{ZnO}$ films showed a rough surface topography with tiny grains distributed over the smooth background. However, with increase of Fe content in the films, the grains were unevenly distributed with coarseness and agglomeration of grains was occurred due to the clustering of initial nuclei that led to form a compact film surface. A similar morphological behavior was reported by Shinde et al. [26] for Mn-doped $\mathrm{ZnO}$ thin films synthesized by spray pyrolysis process. 

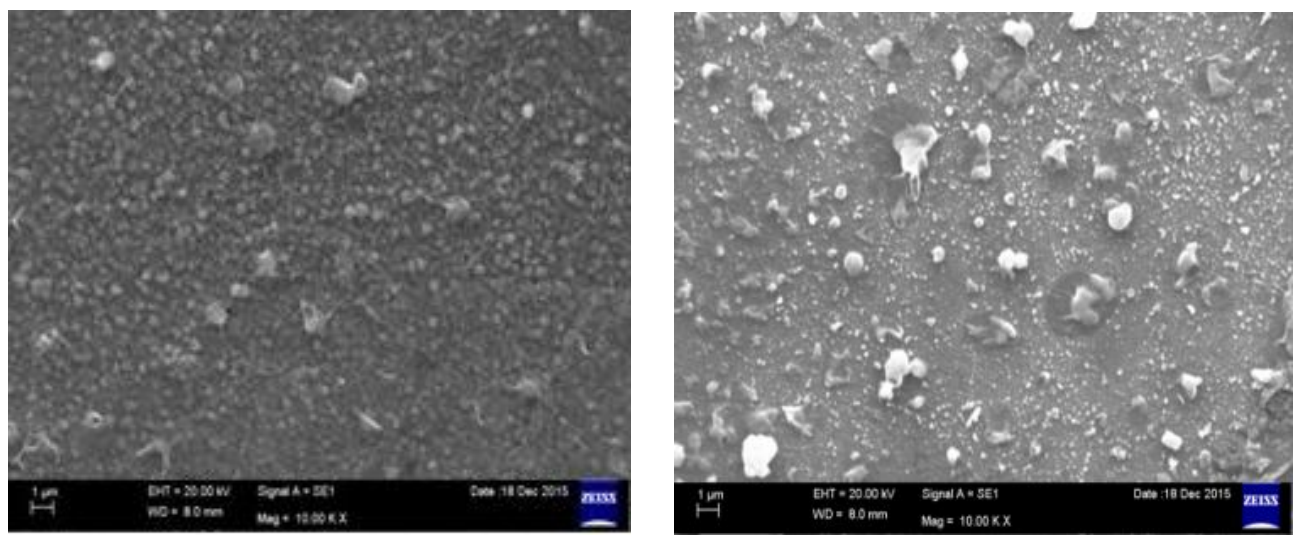

Fig.5:- SEM images of pure and $\mathrm{Fe}=1$ at. \% doped $\mathrm{ZnO}$ films.

\section{Photoluminescence studies:-}

In general, the photoluminescence (PL) emission spectra of thin films can be taken in two ways that is near band emission (NBE) and deep level emission (DLE) [27]. In the present work, the NBE spectra have been taken for all the as-grown FZO layers at room temperature by using $330 \mathrm{~nm}$ as its excitation wavelength. The PL emission spectra of pure and FZO films were shown in figure 6. From the figure, the spectra exhibited an intense UV emission peak at $382 \mathrm{~nm}$ along with a broad green emission peak at $542 \mathrm{~nm}$ for undoped ZnO layers. The UV emission raised due to the recombination of free excitons through an exciton-exciton collision process, while the green emission is due to oxygen vacancies or interstitials present in the layers [28]. The PL spectra clearly represent the effect of increasing Fe content in $\mathrm{ZnO}$ host by showing a peak shift in UV emission. It is observed that the peak is initially shifted towards lower wavelength side (for Fe-content $\leq 2$ at. \%) and then to higher wavelength side (for Fe-content $>2$ at. \%) by quenching the intensity of peak with the increment of Fe concentration in the films. This variation in peak position and intensity might be due to high Fe-doping effect, while the broad green emission peak was found to be suppressed upon Fe-doping.

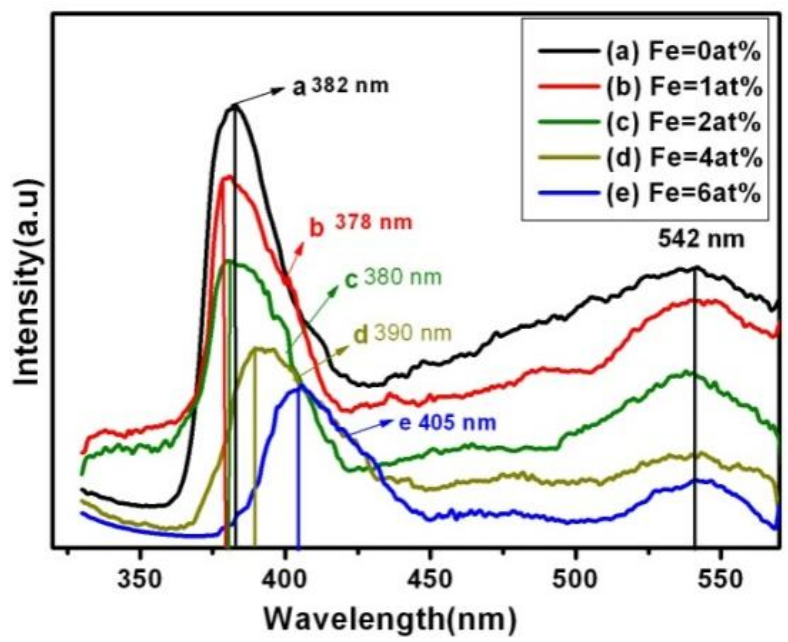

Fig.6:- Photoluminescence spectra of pure and FZO films.

Moreover, the energy of intense peak in the PL spectra can directly give the energy band gap details of the material, following the relation $\mathrm{E}=\mathrm{h} v$. In the present study, as there is a shift in the intense emission peak, the evaluated band gaps from PL spectra are $3.24 \mathrm{eV}, 3.27 \mathrm{eV}, 3.26 \mathrm{eV}, 3.17 \mathrm{eV}$ and $3.05 \mathrm{eV}$ for $\mathrm{Fe}=0,1,2,4$ and 6 at. \% doped $\mathrm{ZnO}$ films respectively. The PL data observed in this work on FZO films were comparable with the reports of Chen et al. [20], Wang et al. [29] and Zhang et al. [30], who studied the PL characteristics of FZO films prepared by RF magnetron sputtering and sol-gel methods respectively. 


\section{Conclusions:-}

Pure and $\mathrm{Fe}$-doped $\mathrm{ZnO}$ thin films have been prepared by using chemical spray pyrolysis process at $400^{\circ} \mathrm{C}$ substrate temperature with different doping concentrations that vary in the range, $1-6$ at. $\%$. The XRD patterns revealed that all the as-grown films belong to hexagonal wurtzite crystal structure that indicates no structural deformation in the $\mathrm{ZnO}$ lattice upon Fe-doping. The PL studies showed slightly higher energy band gap values for lower Fe-doped $(\leq 2$ at. \%) $\mathrm{ZnO}$ films than the pure and highly Fe-doped $\mathrm{ZnO}$ films. Among all the as-grown films, $\mathrm{ZnO}$ films with Fedoping concentration of 1 at. \% exhibited better crystallinity with wider band gap of $3.27 \mathrm{eV}$ than other films, which are suitable for optoelectronic device applications.

\section{References:-}

1. Lee YJ, Ruby DS, Peters DW, McKenzie BB and Hsu JWP,Nano. Lett., 8 (2008) 1501-1505.

2. Gonzalez-Valls I and Lira-Cantu M. Vertically-aligned nanostructures of $\mathrm{ZnO}$ for excitonic solar cells: a review,Energy Environ. Sci. 2 (2009) 19-34.

3. Chen JY and Sun KW,Sol. Energy Mater. Sol. Cells, 94 (2010) 930-934.

4. $\quad$ Krebs FC, Gevorgyan SA and Alstrup J.A, J. Mater. Chem., 19 (2009) 5442-5451.

5. Janotti, A. and Van de Walle, C.G. Fundamentals of zinc oxide as a semiconductor,Rep. Prog. Phys., 72 (2009) $126501-126529$.

6. $\quad$ R.N. Joshi, V.P. Singh and J.C. McClure, Thin Solid Films, 257 (1995) 32.

7. M. Fantini and I. Torriani, Thin Solid Films, 138 (1986) 255.

8. H. Morkoç and U. Ozgur, Zinc Oxide: Fundamentals, Materials and Device Technology; Wiley-VCH Berlin, Germany, (2009) 246.

9. S.J. Pearton, D.P. Norton, K.Ip, Y.W. Heo and T. Steiner, Progressin Materials Science, 50 (2005) 293-340.

10. A.B. Djurisic, X. Chen, Y.H. Leung and A. Man Ching Ng, Journal of Materials Chemistry, 22 (2012) 6526-6535.

11. F. Decremps, J. Pellicer-Porres, A.M. Saitta, J. Chervin, and A. Polian, Physical Review B: Condensed Matter and Materials Physics, 65 (2002) 092101-092105.

12. A. Gotkas, I.H. Mutlu and Y. Yamada, Super lattices and Microstructures, 57 (2013) 139-149.

13. A.P. Rambu, V. Nica and M.Dobromir, Super lattices and Microstructures, 59 (2013) 87-96.

14. C. Aydin, M.S. Abd El-sadek, KaiboZheng, I.S. Yahia and F. Yakuphanoglu, Optics \& Laser Technology, 48 (2013) $447-452$.

15. A.K. Mishra and D. Das, Material Science and Engineering B, 171(2010) 5-10.

16. D. Sibera, R. Jedrzejewski, J. Mizeracki, A. Presz, U. Narkieqicz and W. Lojkowski, ActaPhysicaPolonica A, 116 (2009) 133-135.

17. DhimanPooja, S.K. Sharma, M. Knobel, Ritu Rani and M. Singh, Research Journal of recent Sciences, 1 (2012) 4852.

18. Jianwei Wang, Jiaqi Wang andKezheng Chen, Materials Letters, 64 (2010) 2373-2375.

19. I. Soumahoro, R. Moubah, G. Schmerder, S. Colis, M. AitAouaj, M. Abd-lefdil, N. Hassanain, A. Berrada and A. Dinia, Thin Solid Films, 518 (2010) 4593-4596.

20. A.J. Chen, X.M. Wu, Z.D. Sha, L.J. Zhuge and Y.D. Meng, Journal of Physics D: Applied Physics, 39(2006) $4762-$ 4765 .

21. Karmvir Singh, Vanita Devi, Rakesh Dhar and Devendra Mohan, Super lattices and Microstructures, 85 (2015) 433 437.

22. U. Alver, T. Kilinc, E. Bacaksiz and S. Nezir, Material Science and Engineering, 138 (2007) 74-77.

23. C. Zegadi, A. Abderrahmane, A. Djelloul, S. Hamzaoui, M. Adnane, D. Chaumont and K. Abdelkebir, International Review of Physics, 9 (2015) 39-45.

24. Nanda Shakti and P.S. Gupta, Applied Physics Research, 2 (2010) 19-28.

25. S. Ilican, M. Caglar and Y. Caglar, Materials Science- Poland, 25 (2007) 709-718.

26. V.R. Shinde, T.P. Gujar, C.D. Lokhande, R.S. Mane and Sung-Hwan Han, Materials Chemistry and Physics, 96 (2006) 326-330.

27. W. Shan, W. Walukiewicz, J.W. Ager, K.M. Yu, H. Yuan, H.P. Xin, G. Cantwell, and J.J. Song, Appl. Phys. Lett., 86 (2005) 191911- 191913.

28. K. Uma, S. Ananthakumar, R.V. Mangalaraja, K.P.O. Mahesh, T. Soga and T. Jimbo, J. Sol-Gel Sci. Technol., 49 (2009).

29. Changzheng Wang, Zhong Chen, Ying He, Lanying Li and Dong Zhang, Applied Surface Science, 255 (2009) 68816887.

30. Yongzhe Zhang, Lihui $\mathrm{Wu}$, Hui Li, Jinhai Xu, Lizhong Han, Bochong Wang, Zhongliang Tuo and Erqing Xie, Journal of Alloys and Compounds,473 (2009) 319-322. 